\title{
The role of melatonin in the development of gestational diabetes
}

\begin{abstract}
This review summarizes the literature on melatonin production and its role in the regulation of carbohydrate metabolism, mechanisms of functional relationships between melatonin, insulin, glucagon and circadian organization of the pancreas. The results of experimental and clinical studies have shown that the basis for the development of gestational diabetes is low production of melatonin and the lack of its circadian rhythm in women with abnormal neuroimmunoendocrino system that determines the possibility of prediction and prevention of this complication of pregnancy.

This review summarizes many of the published reports about the production of melatonin and its role in regulation of carbohydrate metabolism, interrelationships between melatonin, insulin, glucagon and diurnal signaling the blood-glucoseregulating of the islet. The results of experimental and clinical investigations support that low melatonin levels and absence of its circadian rhythm, play the role in the development of gestational diabetes mellitus in women with pathology of neuroimmunoendocrinology system and suggest the possibility of prognosis and Prophylaxis for this complication of pregnancy.
\end{abstract}

Keywords: melatonin, gestational diabetes mellitus, insulin, circadian rhythm
Volume I Issue 4 - 2018

\author{
EK Aylamazyan, II Evsyukova, MI \\ Yarmolinskayai \\ Research Institute of Obstetrics, Gynecology, Russia
}

Correspondence: EK Aylamazyan, Research Institute of Obstetrics, Gynecology, St Petersburg, Russia, Email eevs@yandex.ru

Received: June 18, 2018 | Published: July 13, 2018

\section{Introduction}

Increase in the frequency of gestational diabetes mellitus (GDM) and its adverse consequences for mother and child dictates the need to study the mechanisms underlying the development of pregnancy complications. ${ }^{1-5}$ It is known that, in the course of physiological pregnancy there are moderate hyperinsulinemia and insulin resistance associated with an increased need for insulin as a result of the restructuring of metabolic processes in the female body, designed to ensure optimal delivery of nutrients to the developing fetus is thus observed to increase insulin biosynthesis, increased stimulated glucose secretion and increase in mass of pancreatic $\beta$-cells. ${ }^{6}$ However, the question arises: why the number of pregnant pancreatic function is not sufficient to accommodate the metabolic needs during pregnancy, blood glucose levels rise to pathological variables and diagnosed with diabetes? Since the frequency of GDM varies considerably among ethnic populations, and its growth is in direct proportion to the increase of type 2 diabetes, which develops later in life in survivors of HSD (Health Search Database), the attention of researchers in recent years, attracted to the study of genetic factors predisposing to this complication of pregnancy. ${ }^{7}$ A number of genetic variants that may explain some of the individual features of the predisposition to HSD, ${ }^{8,9}$ include different genes (PPARG, KICNJ11, TCF2 / HNF1B, WFS1, HNF4A), dysfunction associated with insulin secretion of pancreatic $\beta$-cells with gestational diabetes and type 2 diabetes. ${ }^{10}$ In addition, it discusses the role of epigenetic modifications activity of genes involved in the regulation of glucose metabolism and insulin secretion occurring during sleep disorders, in a pregnant woman, the night shift, low physical activity, etc. ${ }^{7,11}$ At the same time, numerous studies have shown that GDM risk is present in obese women, ${ }^{12,13}$ the metabolic syndrome, ${ }^{14,15}$ PCOS, endometriosis ${ }^{16}$ as well as in having a history of miscarriage due to hormonal causes ${ }^{17}$ HSD previous pregnancy complications. ${ }^{7,10,18}$ The results of our investigations have revealed the disease three or more functional systems (endocrine, cardiovascular, immune, gastrointestinal tract) in $85 \%$ of mothers whose pregnancy was complicated by gestational diabetes. This suggests that they have a diffuse pathology neuroimmunoendocrinosystem, which is a leading hormone melatonin - homeostasis regulator providing a functional relationship between mechanisms. ${ }^{19,20}$ It should be emphasized that for all the above forms of disease, determining the risk of developing GDM, researchers have noted a low level of melatonin in the body, and its violation of the circadian changes. ${ }^{21-28}$ Melatonin is synthesized from pinealocytes in pineal gland, the endocrine function of which is controlled by the suprachiasmatic nuclei of the hypothalamus and has a diurnal rhythm. Light information from the retinal ganglion cells through retino-hypothalamic tract enters the suprachiasmatic nuclei ( $\mathrm{SCN}$ ) of the hypothalamus, where the signals are in the upper cervical ganglia and then sympathetic noradrenergic pathways reach epiphysis, where melatonin is synthesized. Light inhibits the production and secretion of melatonin, so its maximum level in the epiphysis and human blood is observed during night, and the minimum, in the afternoon. ${ }^{29,30}$ Availability circadian rhythm of melatonin production is a marker of normal operation endogenous circadian biorhythm regulation and synchronization with the external circadian rhythm of alternation between day and night. ${ }^{19,31-33}$

Melatonin is produced not only in the epiphysis. Ekstrapinealny melatonin was found in all organs: the gastrointestinal tract, liver, kidneys, adrenal glands, heart, thymus, gonads, placenta, uterus, platelets, eosinophils, leukocytes, and other cells of the immune system. ${ }^{34,35}$ Thus, its synthesis in mitochondria of eukaryotic cells indicates unique protection of melatonin cellular organelles from oxidative damage and maintaining their physiological functions. ${ }^{36-38}$ Melatonin is synthesized from the amino acid tryptophan by hydroxylation of which (an enzyme tryptophan hydroxylase) and decarboxylation (the enzyme 5-ksitriptofandekarboksilaza) is 
converted into serotonin. Using enzymes $\mathrm{N}$-acetyltransferase (NAT) and oxindole-O-methyltransferase (HIOMT) formed of serotonin, melatonin. From pinealocytes, pineal melatonin is released into the blood and cerebrospinal fluid, whereas melatonin secreted by other cells in the body, enters the blood in small amounts, giving a field of its synthesis paracrine and autocrine effect. ${ }^{39}$ With a hydrophilic molecule of melatonin at the same time, it is highly lipophilic and therefore easily penetrates the blood-brain and the placental barrier, takes place in the capillaries, where $70 \%$ of melatonin binds to albumin. The half-life of melatonin ranges from 30 to 45 minutes. ${ }^{40}$ Melatonin is metabolized in the liver and kidneys. The end products of metabolism are 6-sulfatoksi-melatonin and acetylsalicylic acid. ${ }^{29,39}$ Melatonin provides regulating effect through specific G-protein linked membrane receptors (MT1, MT2, MT3) and nuclear receptors (ROR $\alpha)$, ${ }^{38,41}$ which are found in the suprachiasmatic nuclei of the hypothalamus, the cerebellum, retina, spleen, pancreas, liver, mammary gland, uterus, thymus, gastrointestinal tract, platelets, lymphocytes. ${ }^{39,42-44}$ More than 75 years ago, the role of the pineal gland peptide, called "pinealinom" in the regulation of carbohydrate metabolism was first reported. ${ }^{45}$ It was identified with insulin-like hypoglycemic, anabolic and anticholesterol effects. ${ }^{40}$ In the following decades, numerous experimental studies were performed at the molecular level, the mechanisms established functional connections between melatonin, insulin and glucagon. ${ }^{40,45}$ The pancreas tissue revealed membrane MT1, MT2 and G-protein associated (GPR50) receptors, as well as mRNA nuclear receptors through which melatonin performs a modulating effect on the insulin and glucagon secretion. ${ }^{46-48}$ Furthermore, in the pancreas as well as in other tissues, there are autonomous circadian genes (Bmal, Clock, Per1, Cry1), through which is realized the impact synchronizing circadian rhythm of melatonin on epiphyseal $\beta$ - and $\alpha$-cells. ${ }^{49}$ At night there is a high production of melatonin, but lower insulin secretion, and at day on the contrary. ${ }^{31,50}$ Melatonin stimulates the secretion of glucagon pancreatic $\alpha$-cells, which defines the circadian rhythm of production and glucose metabolism. ${ }^{49,51}$ The effect of melatonin on pancreatic $\alpha$ - and $\beta$-cells and insulin secretion is provided through a complex type of intercellular and intracellular signalling pathways. ${ }^{52}$ Furthermore, melatonin protects pancreatic cells from free radical damage by the elimination of free radicals and activates antioxidant enzymes..$^{31,37,53}$ The circadian amplitude of the melatonin level decreases with age, especially when working and active lifestyle at night, and sleep disorders, resulting in hyper insulinemia, insulin resistance, and hyperglycemia, i.e. symptoms characteristic of type 2 diabetes. ${ }^{54-57}$ The development of these pathological conditions with low production of melatonin and absence of its circadian rhythm are associated with impaired regulation of synthesis and secretion of insulin from $\beta$-cells of the pancreas and its binding to the receptor membranes of the target cells, suppression of expression GLYUT4 gene and decrease of the protein content. ${ }^{58,59}$ The experiment demonstrated that the removal of the epiphysis in insulinsensitive tissues (white and brown adipose tissue, skeletal and cardiac muscle) sharply decreases GLYUT4 mRNA (GLUT4 mRNA), and the content of microsomal membrane protein. Furthermore, in the absence of melatonin disrupted insulin receptor function, in particular, MT2 adipocytes in adipose tissue, dramatically reduces glucose uptake by these cells. ${ }^{60,61}$ Identified pinealectomy effects disappeared as a result of treatment with melatonin. ${ }^{62,63}$ Thus, melatonin epiphyseal is required for the synthesis, secretion and insulin implementation functions. Reducing its production leads to disruption of circadian rhythms of metabolic processes in the body and the development of the pathological condition of the energy balance, obesity, insulin resistance and impaired glucose tolerance. ${ }^{58}$ The level of melatonin in the blood plasma as well as its synthesis, play the key enzyme activity (AA-NAT) in the pineal gland which is significantly reduced in type 2 diabetes, that underlies excess of pancreatic $\beta$-cells ${ }^{49}$ insulin resistance and impaired glucose tolerance..$^{58}$

Melatonin and its circadian rhythm of secretion is determined for a successful pregnancy and birth of a healthy child. First, the melatonin and its metabolites function as direct absorbers produced during pregnancy of free radicals stimulate antioxidant enzymes, thereby providing a stable protection against free radical damage at the cellular and tissue levels in a single system mother-placenta fetus. ${ }^{64-66}$ In individuals with abnormal neuroimmunoendocrinosystem and initially low production of melatonin, when the body's adaptation to pregnancy, significant activation of free radical oxidation leads to the depletion of antioxidant reserves and primarily melatonin..$^{67,68}$ Not only low levels of melatonin, but violation as a result of oxidative modification of proteins the functional state of its receptors, providing regulation of the production of insulin and glucagon in the $\beta$ and $\alpha$-cells of the pancreas, leading to uncontrolled insulin secretion not only in daytime but also at night. The consequence of these processes is the development of insulin resistance and consequent impairment of glucose tolerance. Besides, $\beta$-cells being unable to adequately secrete sufficient amounts of insulin over long time to compensate for insulin resistance, it also contributes to hyperglycemia. To confirm the role of melatonin in the development of gestational diabetes data researchers set low melatonin secretion and the absence of its daily rhythm in the second and third trimesters of a given pregnancy complications, combined with the sleep disorder, the shortening of a night's sleep and quality features. ${ }^{69,70}$ The changes with gestational diabetes, micro PHA production (microRNAs), which normally has a circadian rhythm. ${ }^{71} \mathrm{It}$ is found that the presence of melatonin receptor gene polymorphism and MTNR1B rs10830963 MTNR1B rs4753426 increases the risk of developing gestational diabetes. ${ }^{72-74}$ This shows that women with GDM, exhibit reduced receptor binding ability GLYUT4 and glucose transport in adipose tissue and skeletal muscle..$^{71,75,76}$ Use of melatonin and stabilization of circadian rhythm, normalize metabolism optimized during pregnancy and fetal development. . $8,49,77$ Thus, the results of experimental and clinical studies have expanded our understanding towards the mechanisms of regulation regarding carbohydrate metabolism and energy metabolism, indicate the possibility of prediction of complications in future pregnancies with diabetes at the stage of family planning and timely implementation of preventive measures, including circadian rhythm normalization of sleep and wakefulness, energy metabolism, antioxidant status, and if necessary treatment with melatonina. In addition, the available data indicate the need for special attention to keeping in obstetric hospitals light conditions for the endogenous production of melatonin, as well as restrictions on the use of its suppressive drugs. ${ }^{78,79}$ Increased in the last decade, the interest of researchers to study the physiological role of melatonin in the reproductive function, gave sample evidence that determine the optimal course of pregnancy, delivery and fetal development, making a promising development of new approaches to its use in obstetrics.

\section{Acknowledgements}

None.

\section{Conflict of interest}

Author declares that there is no conflict of interest. 


\section{References}

1. Fadl HE, Ostlund IK, Hanson US. Outcomes of gestational diabetes in Sweden depending on country of birth. Acta Obstet Gynecol Scand. 2012;91(11):1326-1330.

2. Logutova LS Petruhin VA Bocharov II, Burumkulova FF, Guryev VM, et al. Musorin LN Monitoring of infants born to mothers with gestational diabetes mellitus. Russian Gazette obstetrician. 2013;T13(2):S89-S94.

3. Aylamazyana EK, Geotar M. Sugar rafineries diabetes and reproductive system of female. Guide for Physicians Media. 2017.

4. Chavey A, Kioon Ah, Bailbe D, et al. Maternal diabetes, programming of beta-cell disorders and intergenerational risk of type 2 diabetes. Diabetes Metab. 2014;40(5):323-330.

5. Evsyukova II. Condition of newborn children in modern conditions the treatment of their mothers, diabetics. J Midwifery and Women's Bolezney. 2006;TLV(1):S17-S20.

6. Senat MV, Deruelle P. Gestational diabetes mellitus. Gynecol Obstet Fertil. 2016;44(4):244-247.

7. Fernandez MJL, Rodriguez RS, Menendez TE, et al. The possible role of epigenetics in gestational diabetes: cause, consequence, or both. Obstet Gynecol Intern. 2010:605-613.

8. Scott LJ, Mohlke KL, Bonnycastle LL, et al. A genome-wide association study of type 2 diabetes in finn detects multiple susceptibility variants. Science. 2007;316(5829):1341-1345.

9. Stadek R, Rocheleau G, Rung J, et al. A genome-wide association study identifies novel risk loci for type 2 diabetes. Nature. 2007;445(7130):881885

10. Robitaille I, Grant AM. The genetics of gestational diabetes mellitus evidence for relationship with type 2 diabetes mellitus. Genet Med. 2008;10(4):240-250.

11. Ling C, Groop L. Epigenetics: a molecular link between environmental factors and type 2 diabetes. Diabetes. 2009;58(12):2718-2725.

12. Farrar D, Simmonds M, Bryant M, et al. Risk factor screening to identify women requiring oral glucose tolerance testing to diagnose gestational diabetes: A systematic review and meta-analysis and analysis of two pregnancy cohorts. PLoS One. 2017;12(8):e0175288.

13. Morikawa M, Yamada T, Yamada T, et al. Prevalence of gyperglycemia during pregnancy according to maternal age and pre-pregnancy body mas index in Japan, 2007-2009. Int J Gynaecol Obstet. 2012;118(3):198-201.

14. Baumfeld Y, Novack L, Wiznitzer A, et al. Pre-Conception Dyslipidemia is Associated with Development of Preeclampsia and Gestational Diabetes Mellitus. PLoS One. 2015;10(10):e0139164.

15. Metsala J, Stach LB, Gissier M, et al. Risk of Pregnancy Complications in Relation to Maternal Prepregnancy Body Mass Index: Population-Based Study from Finland 2006-10. Pediatr Perinat Epidemiol. 2015;30(1):2837.

16. Toulis KA, Goulis DG, Kolibianakis CA, et al. Risk of gestational diabetes mellitus in women with polycystic ovary syndrome: a systematic review and meta-analysis. Fertil Steril. 2009;92(2):667-77.

17. Tamas G, Kerenyi Z. Gestational diabetes: current aspects on pathogenesis and treatment. Exp Clin Endocrinol Diabetes. 2001;1099 Suppl 2:S400 S411.

18. Cypryk C, Szymczak W, Czupryniak L, et al. Gestational diabetes mellitus - an analysis of risk factors. Endokrynol Pol. 2008;59(5):393-397.

19. Pandi PSR, Srinivasan V, Maestroni GJM, et al. Melatonin. Nature's most versatile biological signal? FEBS J. 2006;273:281338.
20. Sharafati CR, Shirzad H, Rafieian KM, et al. Melatonin and human mitochondrial diseases. J Res Med Sci. 2017;22:2.

21. Yarmolinskaya MI, Ailamazyan EK. Different facets of the problem. Genital endometriosis. 2017;615.

22. Li C, Shi Y, You L, et al. Melatonin receptor 1Agene polymorphism associated with polycystic ovary syndrome. Gynecol Obstet Invest. 2011;72(2):130-134.

23. Kvetnoy IM, Hernandez YJ, Hernandez JM, et al. Diffuse neuroendocrine system and mitochondrial diseases: molecular and cellular bases of pathogenesis, new approaches to diagnosis and therapy. Neuro Endocrinol Lett. 2000;21(2):83-99.

24. Saha L, Kaur S, Saha PK. Pharmacotherapy of polycystic ovary syndromean update. Fundam Clin Pharmacol. 2012;26(1):54-62.

25.Zito G, Luppi S, Giolo E, et al. Medical treatments for endometriosisassociated pelvic pain. Biomed Res Int. 2014; 191-197.

26. McMullan CJ, Schernhammer ES, Rimm EB, et al. Melatonin secretion and the incidence of type 2 diabetes. JAMA. 2013;309(13):1388-1396.

27. McMullan CJ, Curhan GC, Schernhammer ES, et al. Association of nocturnal melatonin secretion with insulin resistentance in nondiabetic young women. Am J Epidemiol. 2013;178(2):231-238.

28. Reiter RJ, Tan DX, Korkmaz A, et al. Melatonin and stable circadian rhythms optimize maternal, placental and fetal physiology. Hum Reprod Update. 2014;20(2):293-307.

29. Anisimov VN. Melatonin (a role in the body, clinical use). SPb: System; 2007:40.

30. Saper CB. The central circadian timing system. Curr Opin Neurobiol. 2013;23(5):747-751

31. Marcheva B, Ramsey KM, Buhr ED, et al. Disruption of the clock components CLOCK and BMAL1 leads to hypoinsulinaemia and diabetes. Nature. 2010;466(7306):627-631.

32. Reiter RJ, Tamura H, Tan DX, et al. Melatonin and the circadian system: contributions to successful female reproduction. Fertil Steril. 2014;102(2):321-328.

33. Tsang $\mathrm{AH}$, Barclay JL, Oster $\mathrm{H}$. Interactions between endocrine and circadian systems. J Mol Endocrinol. 2014;52(1):R1-R16.

34. Evsyukova HV. Platelets and Aspirin-Induced Asthma: Pathogenes and Melatonin. Joseph M, editor. Elsevier: Academic Press; 2014.

35. Schlabritz LN, Hellner N, Middendorf R, et al. The human myometrium as a target for melatonin. J Clin Endocrinol Metab. 2003;8(2):908-913.

36. Hardeland R, Madrid JA, Tan DX, et al. Melatonin, the circadian multioscillator system and health: the need for detailed analyses of peripheral melatonin signaling. J Pineal Res. 2012;52(2):139-166.

37. Tan DX, Manchester LC, Liu X, et al. Mitochondria and chloroplasts as the original sites of melatonin synthesis: a hypothesis related to melatonin's primary function and evolution in eukaryotes. J Pineal Res. 2013;54(2):127-38.

38. Venegas C, Garcia JA, Escames G, et al. Extrapineal melatonin analysis of its subcellular distribution and daily fluctuations. J Pineal Res. 2012;52(2):217-227.

39. Reiter RJ, Rosales Corral SA, Manchester LC, et al. Peripheral Reproductive Organ Helth and Melatonin: Ready for Prime Time. Int $J$ Mol Sci. 2013;14(4):7231-7272.

40. Claustrat B, Leston J. Melatonin: Physiological effects in humans. Neurochirurgie. 2015;61(2-3):77-84. 
41. Yie SM, Niles LP, Youglai EV. Melatonin receptors on human granulose cell membranes. J Clin Endocrinol Metab. 1995;80(5):1747-1749.

42. Ren W, Liu G, Chen S, et al. Melatonin signallingin T cells: Functionsand applications. J Pineal Res. 2017;62(3):e12394.

43. Vacas MI, Del Zar M, Martinuzzo M, et al. Binding sites for [3H]melatonin in human platelets. $J$ Pineal Res. 1992;13(2):60-65.

44. Kvetnoy IM. Extrapineal melatonin: location and role within diffuse neuroendocrine system. Histochem J. 1999;31(1):1-12.

45. Peschke E, Bahr I, Muhlbauer E. Melatonin and Pancteatic Islets: Interrelationships between Melatonin, Insulin and Glucagon. Int J Mol Sci. 2013;14(4):6981-7015.

46. Castillo Vaquero A, Salido GM, Gonzalez A. Melatonin induces calcium release from CCK-8 and thapsigargin-sensitive cytosolic stores in pancreatic AR42J cells. J Pineal Res. 2010;49(3):256-263.

47. Slominski RM, Reiter RJ, Schlabritz LN, et al. Melatonin membrane receptors in peripheral tissues: Distribution and functions. Mol Cell Endocrinol. 2012;351(2):152-166.

48. Soderquist F, Hellstrom PM, Cunningham J. Human gastroenteropancreatic expression of melatonin and its receptors MT1' and MT2. PLOS ONE. 2015;10(3):e0120195.

49. Peschke E, Bahr I, Muhlbauer E. Experimental and clinical aspects of melatonin and clock genes in diabetes. J Pineal Res. 2015;59(1):1-23.

50. Peschke E, Muhlbauer E, Musshoff U, et al. Receptor (MT (1)) mediated influence of melatonin on Camp concentration and insulin secretion of rat insulinoma cells INS-1. J Pineal Res. 2002;33(2):63-71.

51. Bahr I, Muhlbauer E, Schucht H, et al. Melatonin stimulates glucagon secretion in vitro and in vivo. J Pineal Res. 2011;50(3):336-344.

52. Peschke E, Muhlbauer E. New evidence for a role of melatonin in glucose regulation. Best Pract Res Clin Endocrinol Metab. 2010;24(5):829-841.

53. Li G, Hou G, Lu W, et al. Melatonin protects mice with intermittent hypoxia from oxidative stress-induced pancreatic injury. Sleep Biol Rhythms. 2011;9(s1):78-85.

54. Tasali E, Leproult R, Ehrmann DA, et al. Slow-wave sleep and the risk of type 2 diabetes in humans. Proc Natl Acad Sci USA. 2008;105(3):10441049.

55. Knutson KL, Cauter EV. Associations between Sleep Loss and Increased Risk of Obesity and Diabetes. Ann NY Acad Sci. 2008;1129:287-304.

56. Kvetnoy I. Extrapineal melatonin in pathology: new perspectives for diagnosis, prognosis and treatment of illness. Neuro Endocrinol Lett. 2002;23(supp 1):92-96.

57. Perelis M, Ramsey KM, Marcheva B, et al. Circadian Transcription from Beta Cell Function to Diabetes Pathophysiology. J Biol Rhythms. 2016;31(4):323-336.

58. Cipolla NJ, Amaral FG, Afeche SC, et al. Melatonin, energy metabolism, and obesity: a review. J Pineal Res. 2014;56(4):371-381.

59. Lima FB, Machado UF, Bartol I, et al. Pinealectomy causes glucose intolerance and decreases adipose cell responsiveness to insulin in rats. Am J Physiol. 1998;275(6 Pt 1):E934-E941.

60. Mellado C, Rodriguez V, de Diego JG. et al. Effect of pinealectomy and of diabetes on liver insulin and glucagon receptor concentrations in the rat. $J$ Pineal Res. 1989;6(4):295-306.

61. Nogueira TC, Lellis SC, Jesus DS, et al. Absence of melatonin induces night-time hepatic insulin resistance and increased gluconeogenesis due to stimulation of nocturnal unfolded protein response. Endocrinology. 2011;152(4):1253-1263.
62. Ha E, Yim SV, Chung JH, et al. Melatonin stimulates glucose transport via insulin receptor substrate-I / phosphatidyli nositol 3-kinase pathway in C2C12 murine skeletal muscle cells. J Pineal Res. 2006;41:67-72.

63. Picinato MC, Hirata AE, Cipolla NJ. et al. Activation of insulin and IGF1 signallingpathways by melatonin through MT1 receptor in isolated rat pancreatic islets. J Pineal Res. 2008;44(1):88-94.

64. Galano A, Tan DX, Reiter RJ. On the free radical scavenging activities of melatonin's metabolites, AFMK and AMK. J Pineal Res. 2013;54(3):245257.

65. Korkmaz A, Reiter RJ, Topal T, et al. Melatonin, an established antioxidant worthy of clinical use. Mol Med. 2009;15(1-2):43-50.

66. Lanoix D, Lacasse AA, Reiter RJ, et al. Melatonin: the watchdog of villous trophoblast homeostasis against hypoxia / reoxygenation-induced oxidative stressand apoptosis. Mol Cell Endocrinol. 2013;38(1-2):35-45.

67. Shevelkova AA, Ailamazyan EK, Evsyukova II. Features of oxidative modification of proteins and functional state of erythrocyte in pregnancy complicated by chronic placental insufficiency. J Obstetrics and Gynecol diseases. 2015;TLXIV(5)S62-S68.

68. Tamura H, Takasaki A, Taketani $\mathrm{T}$, et al. Melatonin and female reproduction. J Obstet Gynaecol Res. 2014;40(1):1-11.

69. Shimada M, Seki H, Samejima M, et al. Salivary melatonin levels and sleep-wake rhythms in pregnant women with hypertensive and glucose metabolic disorders: A prospective analysis. BioScience Trends. 2016;10(1):34-41.

70. Tsai SY, Kuo, Lai YH, Lee CN. Factors associated with sleep quality in pregnant A observational study. Nurs Res. 2011;60(6):405-412.

71. Poirier C, Desgagne V, Guerin R, et al. MicroRNAs in pregnancy and gestational mellitus: emerging role in maternal metabolic regulation. Curr Diab Rep. 2017;17(5):35.

72. Zhan Y, Liu F, Li C, et al. Association between single nucleotide polymorphism of rs4753426 of melatonin receptor $1 \mathrm{~B}$ gene and gestational diabetes mellitus. Zhonghua Fu Chan Ke Za Zhi. 2014;49(4):276-280.

73. Tarnowski M, Maliniwski D, Safranow K, et al. MTNR1A and MTNR1B gene polymorphisms in women with gestational diabetes. Gynecol Endocrinol. 2017;33(5):395-398.

74. Vlassi M, Gazouli M, Paltoglou G, et al. The rs10830963 variant of melatonin receptor MTNR1B is associated with increased risk for gestational diabetes mellitus in a Greek population. Hormones (Athens). 2012;11(1):70-76.

75. Zhang B, Jin Z, Sun L, et al. Expression and correlation of sex hormonebinding globulin and insulin signal transduction and glucose transporter proteins in gestational diabetes mellitus placental tissue. Diabetes Res Clin Pract. 2016;119:106-117.

76. Colomiere M, Permezel M, Lappas M. Diabetes and obesity during pregnancy alter insulin signallingand glucose transporter expression in maternal skeletal muscle and subcutaneous adipose tissue. $\mathrm{J} \mathrm{Mol}$ Endocrinol. 2010;44(4):213-223.

77. Sharma S, Singh H, Ahmad N, et al. The role of melatonin in diabetes: Therapeutic implications. Arch Endocrinol Metab. 2015;59(5):391-399.

78. Abd Allah AR, El Sayed SM, Abdel Wahab MH, et al. Effect of melatonin on estrogen and progesterone receptors in relation to uterine contraction in rats. Pharmacol Res. 2003;47(4):349-354.

79. Papagiannidou E, Skene DJ, Ioannides C. Potential drug interations with melatronin. Physiol Behav. 2014;131:17-24. 